\title{
Techno-Economic Analysis of Receiver Replacement Scenarios in a Parabolic Trough Field
}

Marc Röger, Eckhard Lüpfert, Simon Caron, Simon Dieckmann

SolarPACES Conference 2015

Cape Town, 13.-16.10.15

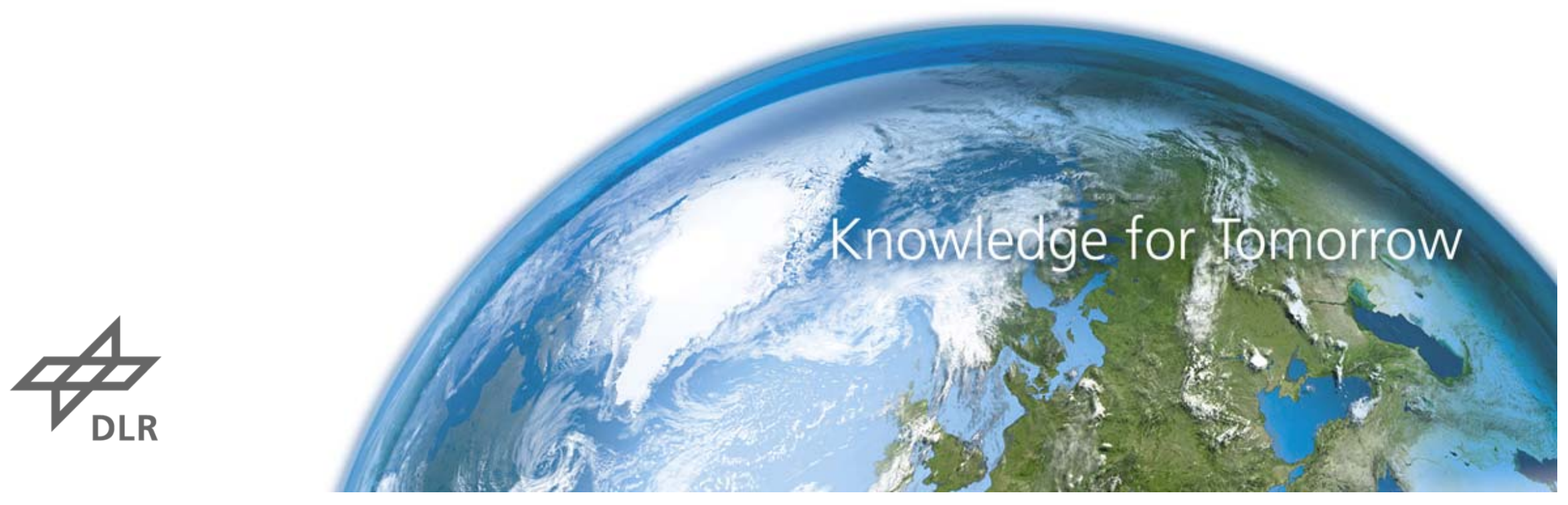




\section{Overview}

1. MOTIVATION of Study

2. REFERENCE Parabolic Trough Plant

3. SCENARIOS for Receiver Performance Loss

4. METHODOLOGY

5. RESULTS

6. CONCLUSIONS 


\section{MOTIVATION of Study}

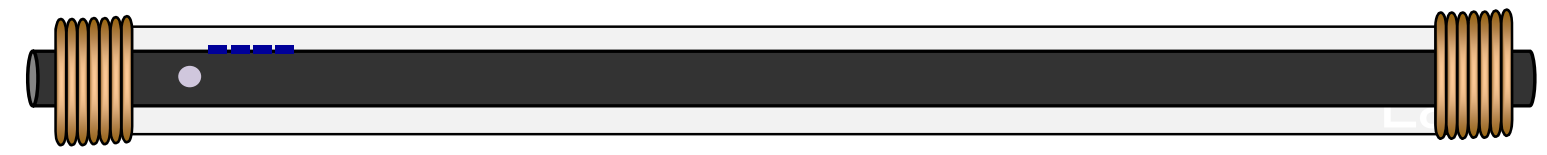

- Field heat losses are between 7\% (Jordan, Ma'an) and $10 \%$ (Guadix, Spain) of the collected solar energy (Eurotrough-type, 70mm absorber, HTF: Oil)

- Receiver design lifetime is 20-40 years

- However, lifetime may be reduced by

- Different maturity of products

- Limited experience in operation, $\mathrm{H}_{2}$ accumulation in HTF

- Increasing temperatures and new fluids

- Wind events with glass breakage

- In case of failure, receiver heat loss may be increased by a factor 5 to 10

- Objective of study: Energetic and economic impact of different receiver performance loss scenarios
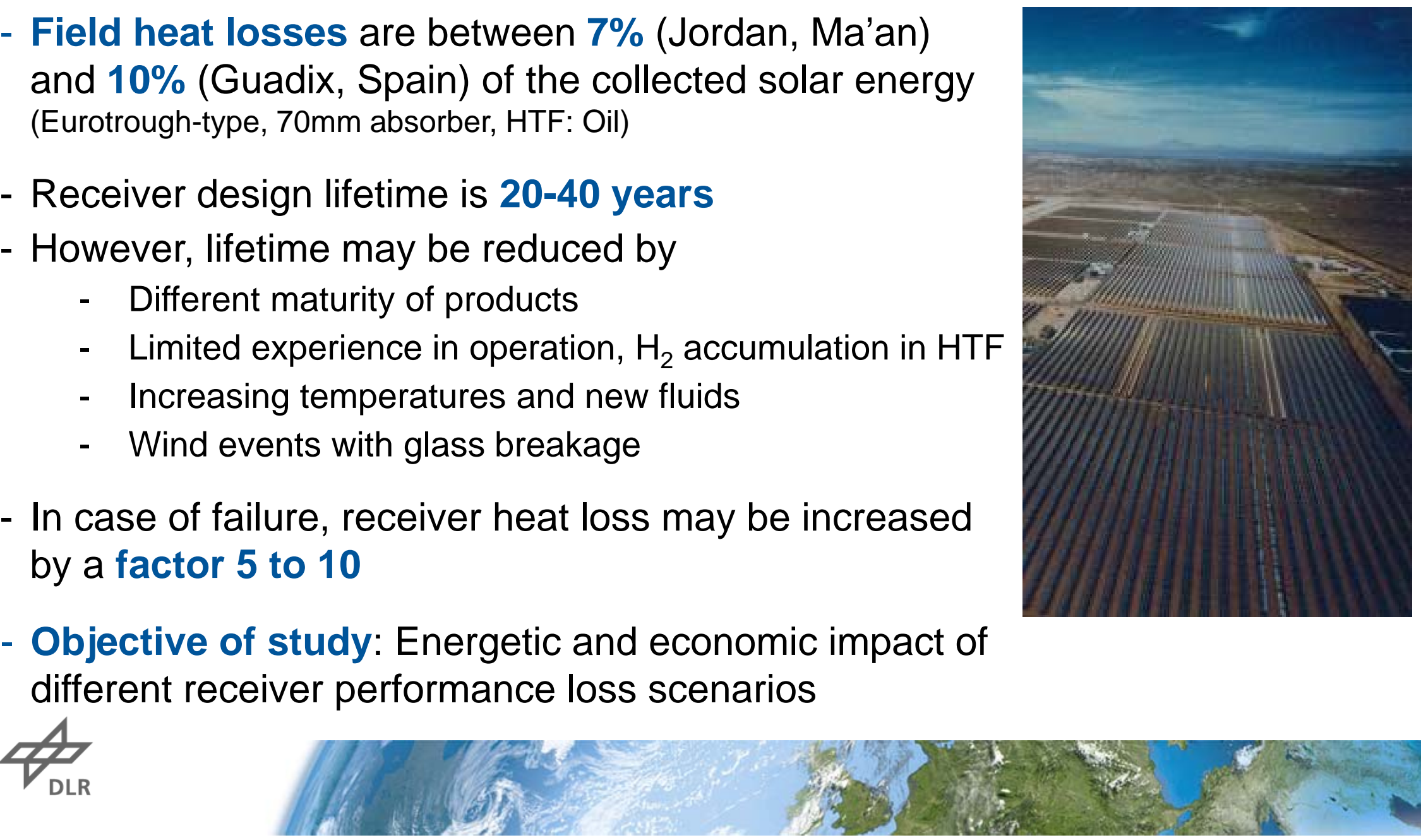


\section{REFERENCE Parabolic Trough Plant}

Technology

- Modern 150-MW $\mathrm{MW}_{\mathrm{el}}$ parabolic trough plant in Ma'an, Jordan (DNI $2820 \mathrm{kWh} / \mathrm{m}^{2} \mathrm{a}$ )

- 7.5h-molten salt storage

- 360 loops of high-quality collectors $\left(\eta_{\text {opt }}=0.78\right)$ (Eurotrough-geometry)

- 51'840 receivers (totaling 207 km), either standard or with Xe-capsule $(+1.3 \%$ solar field cost est.)

- Turbine $150 \mathrm{MW}$, efficiency 38.5\%

- Dry cooling, no fossil firing

\section{Economy}

- Investment costs $4 \mathrm{M} € / \mathrm{MW}_{\mathrm{el}}$

- Annual O\&M + Ins.: 2.4\%*I

- Discount rate 6\%, 25\% equity, $75 \%$ debt (5\% interest rate), 25 yrs operation

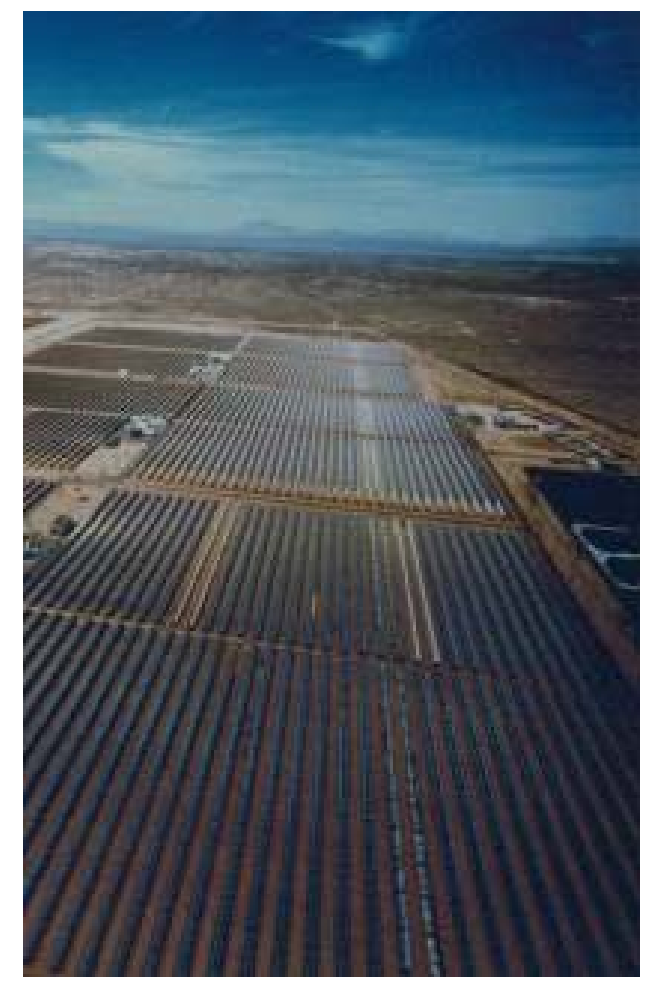

$\rightarrow$ LEC $11.3 € c e n t / k W h_{\text {el }}$ 


\section{SCENARIOS for Receiver Performance Loss}

Event

- "Wind A/B" Wind event destroying glass envelopes

- " $\mathrm{H}_{2}$ " Hydrogen accumulation

- "AR" Anti-reflection coating degradation

Affected Field

- $\quad 50 \%\left(\mathrm{H}_{2}\right)$ or $100 \%(\mathrm{AR})$ of field

- Limits of field (5.6\%, Wind)

Variation of point in time when damage occurs

- sudden event year $t=5,10$, or 15

- gradual damage (AR) $1 . .5,1 . .10,1 . .15$

Different counter measures (full performance in year $t+2$ )

- "Leave" damaged receivers (do nothing)

- "Replace" damaged receivers

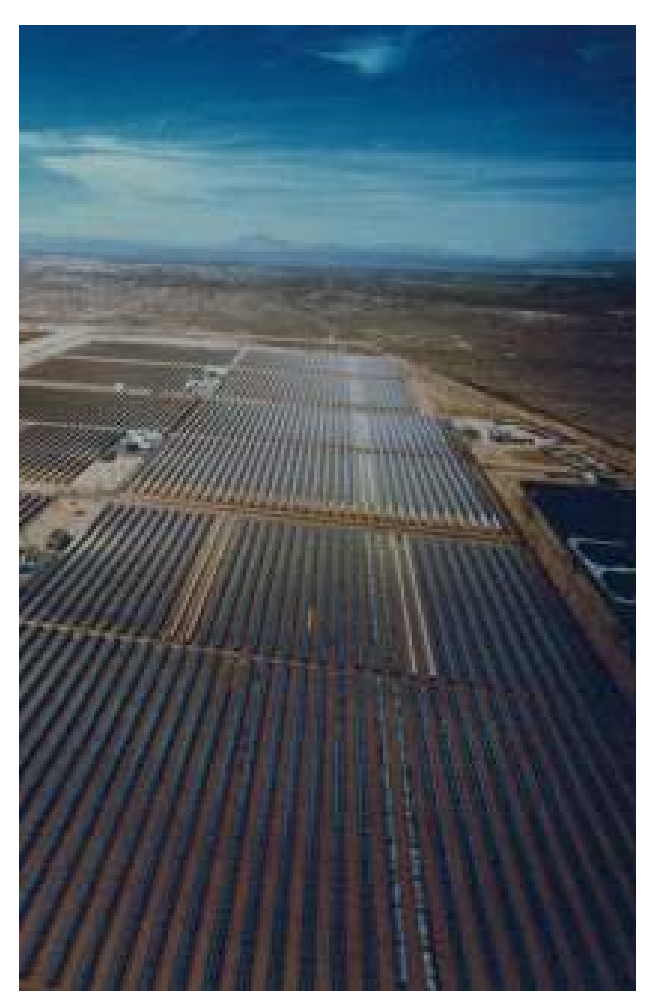

- Activate "Xenon" capsule $\left(\mathrm{H}_{2}\right.$ accumulation)

-Fix" receivers $\left(\mathrm{H}_{2}\right.$ accumulation) 


\section{SCENARIOS for Receiver Performance Loss}

\section{Heat Loss of Regarded Receivers}

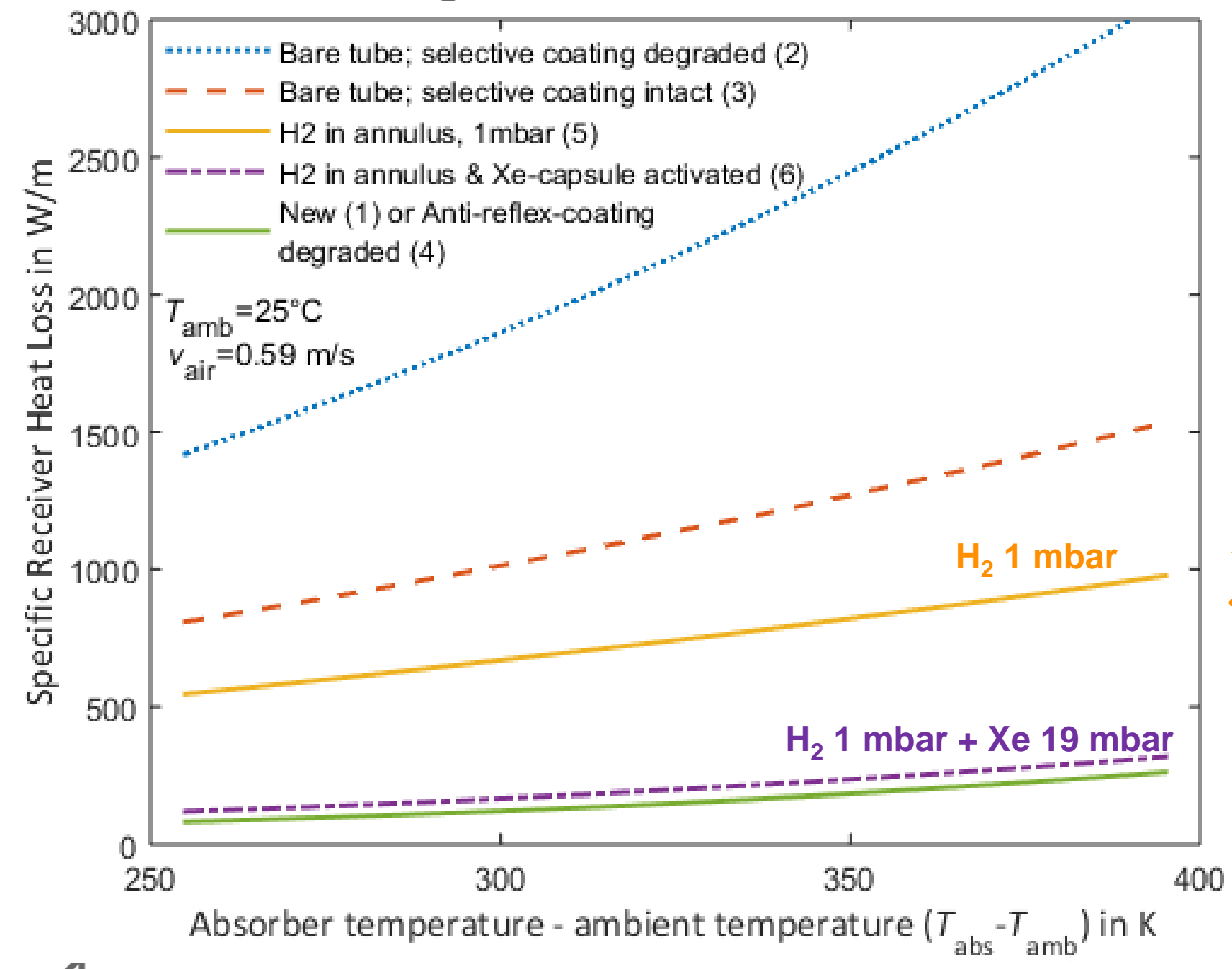

$\tau=100 \% ; \alpha_{\mathrm{sol}}=55 \%$, $\varepsilon=65 \%$, free convection

$\tau=100 \% ; \alpha_{\text {sol }}=96 \%$, $\varepsilon=8-9 \%$, free convection

$\tau=97 \% ; \alpha_{\text {sol }}=96 \%$, $\varepsilon=8-9 \%, h_{\mathrm{ann}}=12.4 \mathrm{~W} / \mathrm{m}^{2} \mathrm{~K}$

$\tau=97 \% ; \alpha_{\mathrm{sol}}=96 \%$, $\varepsilon=8-9 \%, h_{\mathrm{ann}}=\mathbf{0 . 8} \mathrm{W} / \mathrm{m}^{2} \mathrm{~K}$ $\tau=97 / 92 \% ; \alpha_{\text {sol }}=96 \%$, $\varepsilon=8-9 \%, h_{\mathrm{ann}}=0.0 \mathrm{~W} / \mathrm{m}^{2} \mathrm{~K}$
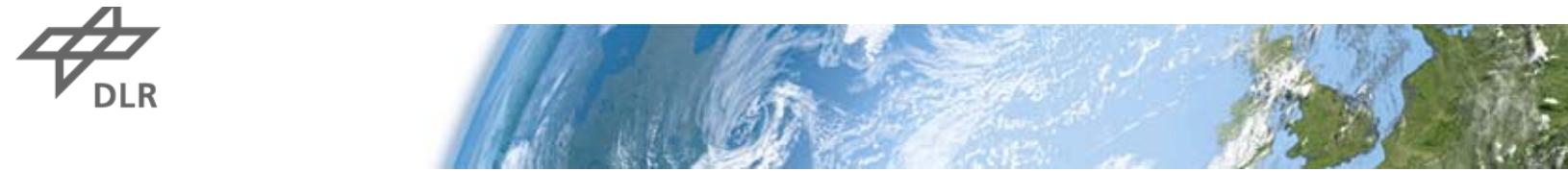


\section{SCENARIOS for Receiver Performance Loss Heat Loss of Regarded Receivers}

Wind strongly influences bare and $\mathrm{H}_{2}$ receivers. Increase of air speed near receivers from 0.6 to $3.0 \mathrm{~m} / \mathrm{s}$ leads to higher heat losses:

- With intact envelope $+6 \mathrm{~W} / \mathrm{m}$

- $\mathrm{H}_{2}$ accumulation $\quad+100 \mathrm{~W} / \mathrm{m}$

- Bare tubes with broken envelope $+1000-2000 \mathrm{~W} / \mathrm{m}$

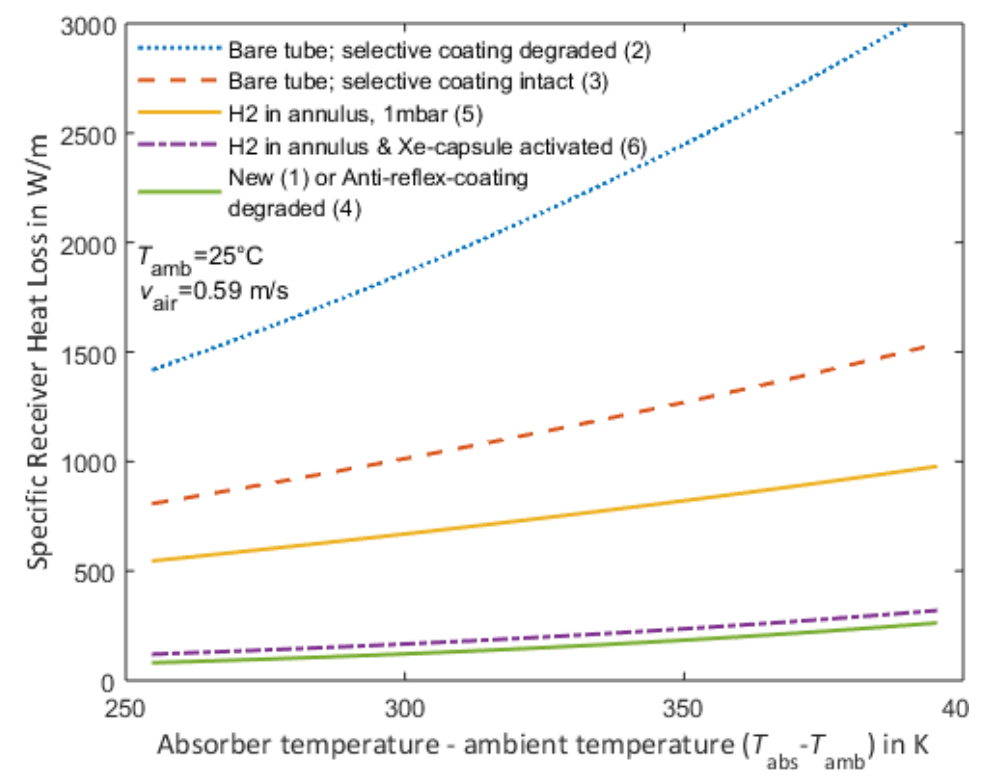

Relation between air speed interacting with receivers and $10 \mathrm{~m}$ wind speed derived from measurements of [Dudley]

V. Dudley, G. Kolb, M. Sloan, D. Kearney, "Test Results, SEGS LS-2 Solar Collector," Sandia National Laboratories, Report SAND94-1884, Dec. 1994

- 10m wind speed of $3.8 \mathrm{~m} / \mathrm{s}$ (Ma'an) $\rightarrow 0.6 \mathrm{~m} / \mathrm{s}$ air speed near receivers
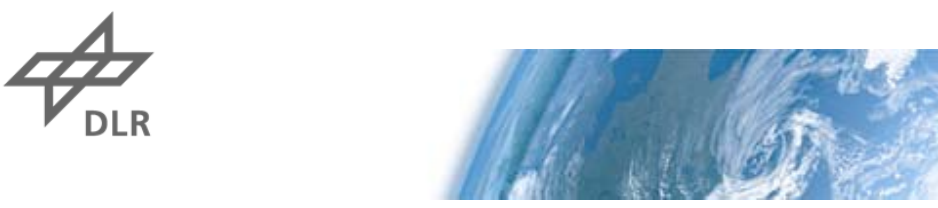


\section{METHODOLOGY}

\section{greenius + Matlab}

Software greenius (http://freegreenius.dlr.de)

- Performance calculations of CSP \& other renewable systems based on hourly plant performance simulations

Special version created to represent

- Spatially inhomogeneous collector loops

- Temporal variation of optical and thermal receiver quality

- Additional investments for repair at specific points in time $t+1$ possible

- Calculation of each year

- greenius start from DOS I Matlab prompt and preparation of input files and postprocessing with Matlab

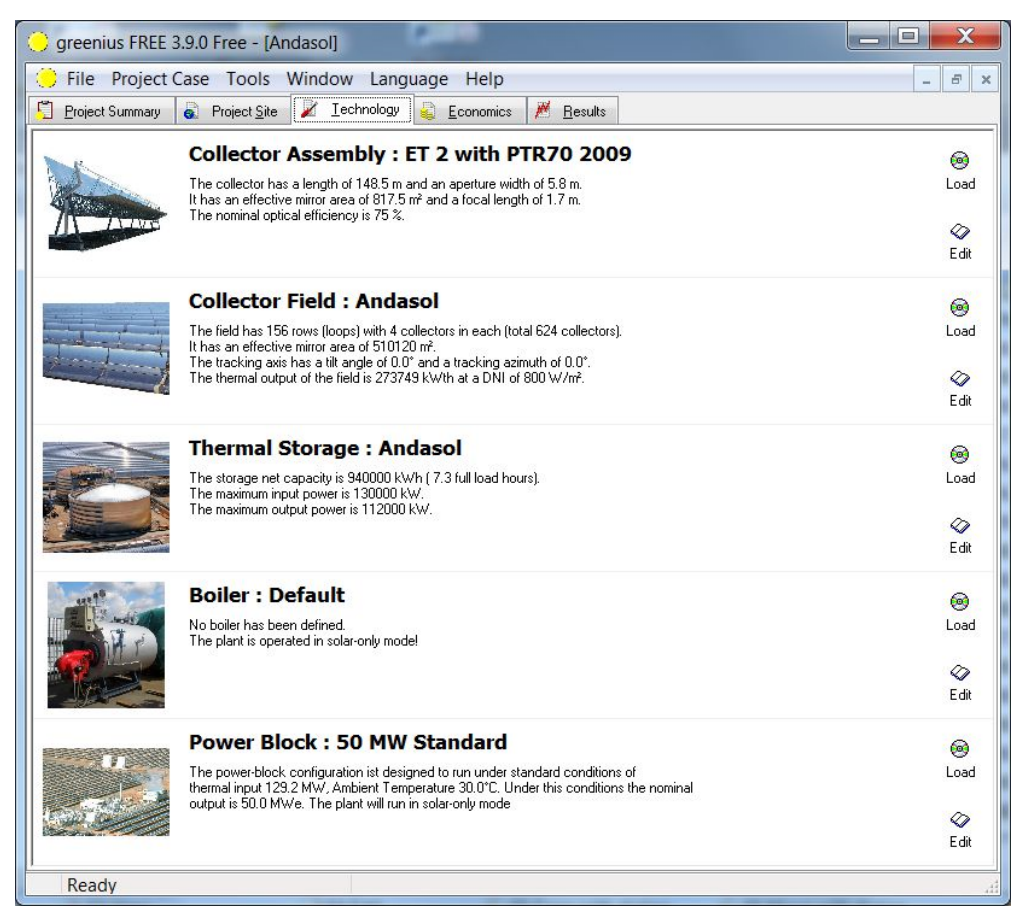

processing with Matlab

greenius 


\section{RESULTS}

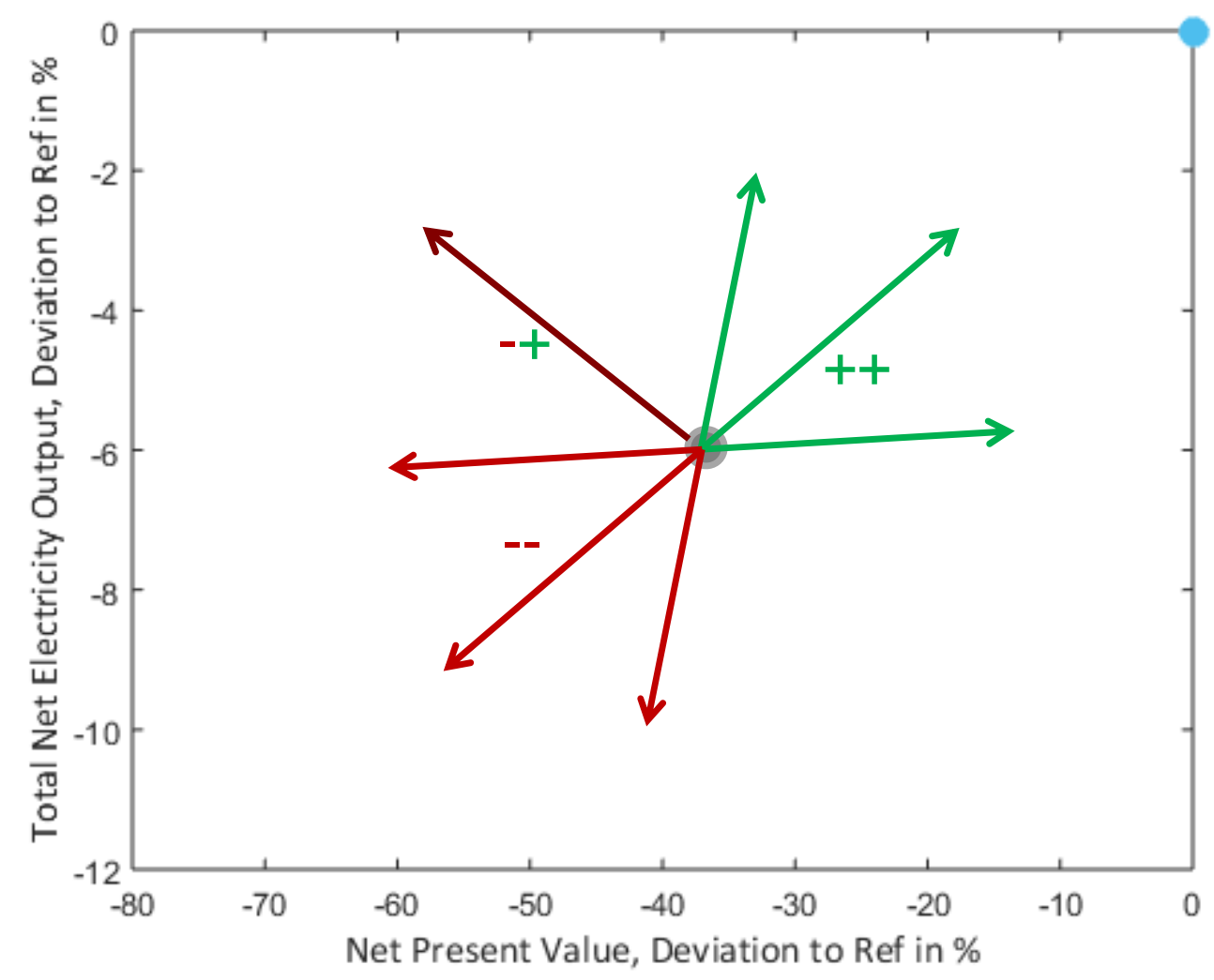

Net Present Value ( $x$-axis)

- is the discounted value of the cumulated project cash flows at time zero

- is a measure for economic success of a project

Total Net Electricity Output (y-axis)

- is the total net electrical output of the plant over 25 years

Plotted is the deviation to the reference scenarios

('Ref' or 'Ref-Xe')

For maximum electricity production and maximum economic success

$\rightarrow$ move right and up
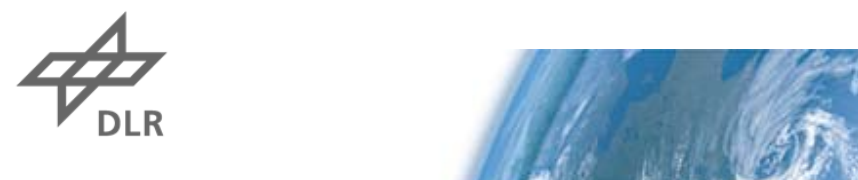


\section{RESULTS}

Wind ('A'/'B' ) and Anti-reflection Coating ('AR') Scenarios

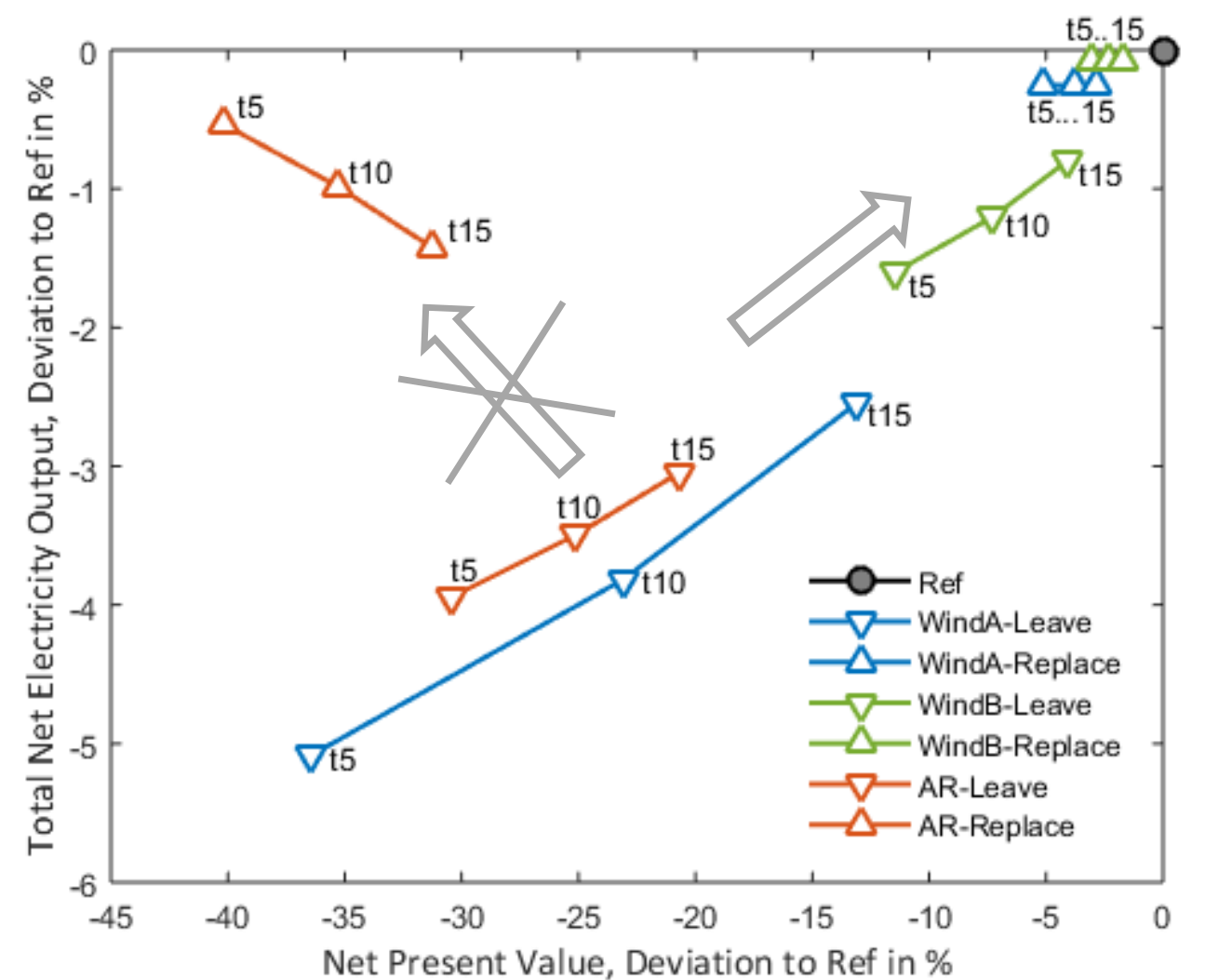

- WindA (degr. coating) event may reduce net present value up to $36 \%$ and total generated electricity up to $5 \%$ over plant lifetime

- Replacement* is both economically and energetically viable

- WindB (stable coating) is similar but less pronounced

- AR scenario may reduce net present value up to $30 \%$ and electr. up to $4 \%$

- Replacement* is energetically *Replace: $\sim 1 \mathrm{k} € /$ rec. (rec. $600 €+$ labour $400 €+$ Loop outage) viable, but economically NOT

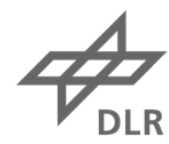
viable 


\section{RESULTS}

Hydrogen Scenarios ('H2')

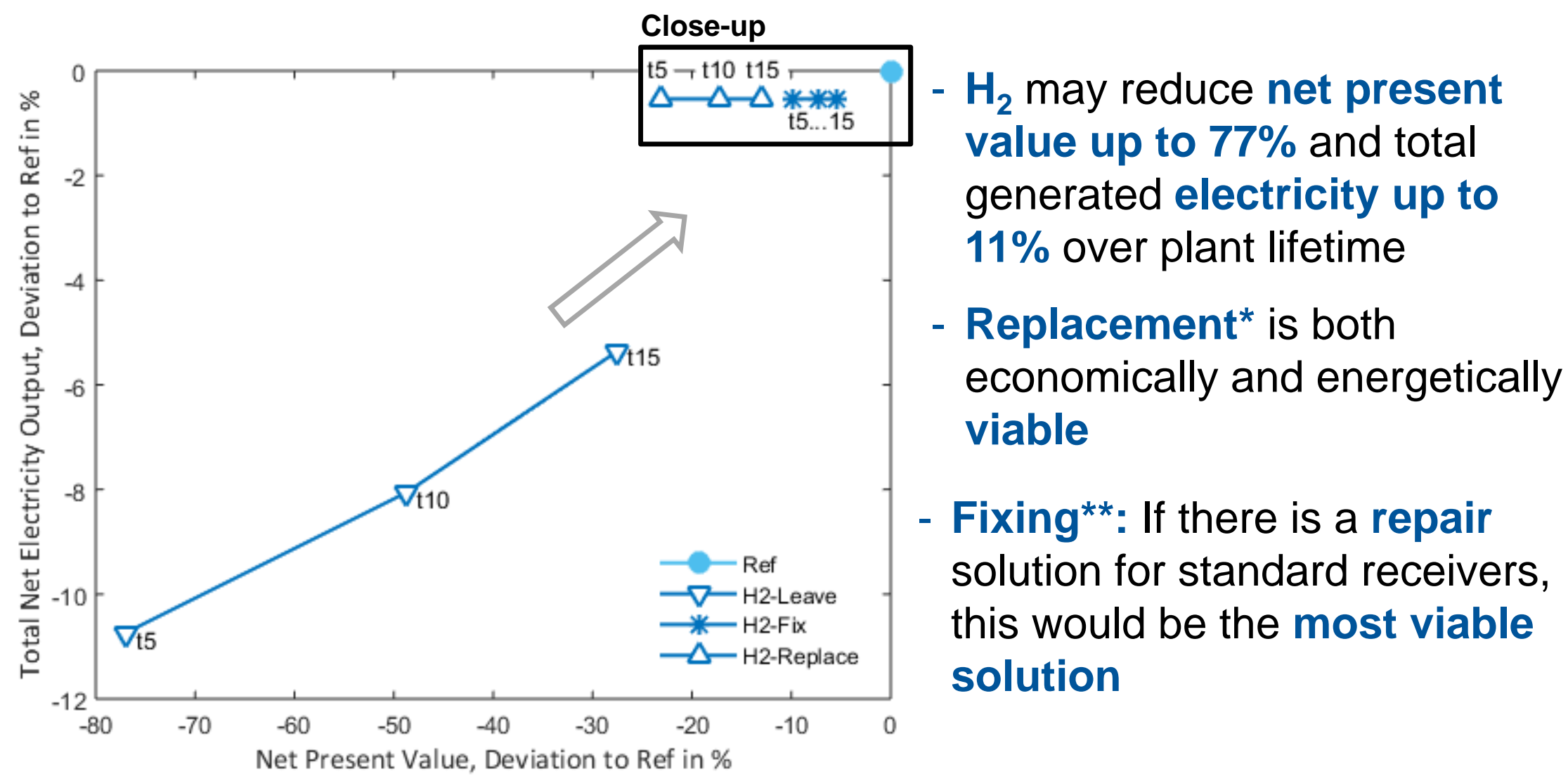

*Replace: $\sim 1 \mathrm{k€/rec}$. (rec. $600 €+$ labour $400 €+$ Loop outage)

**Repair/Fix : 200€/rec. assumed

1
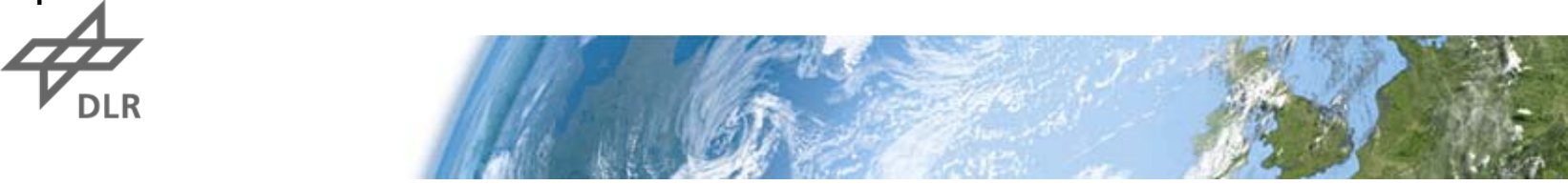


\section{RESULTS}

Hydrogen Scenarios ('H2')

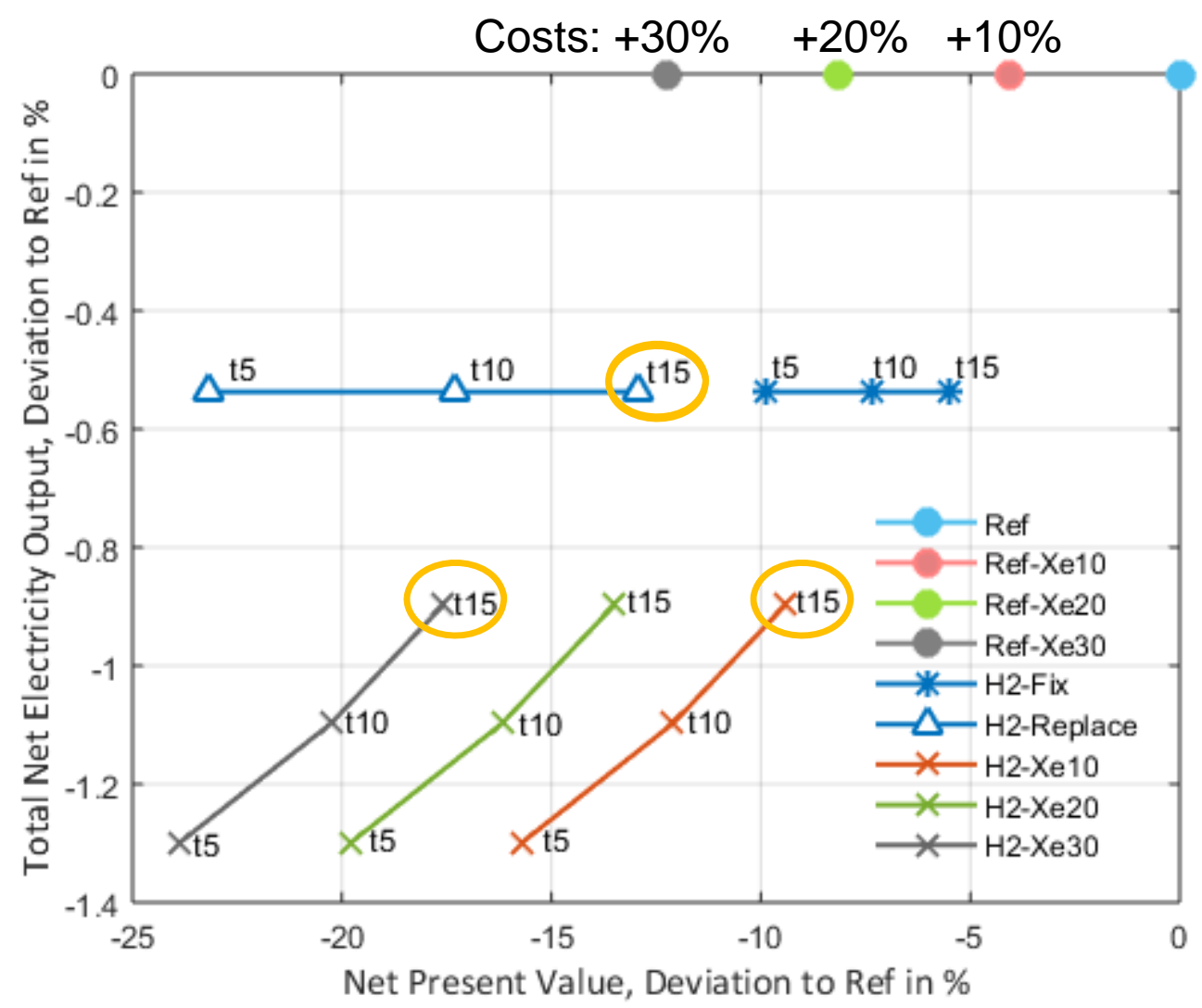

Xe receivers:

- Reference 'Ref-Xe' scenarios have lower net present value, because of higher initial investment

- Xe10 / Xe20 / X30: surplus of $+10 \%$ / 20\% / 30\% costs compared to standard receivers

- Xe10: In case of $\mathrm{H}_{2}$ accumulation, 'H2-Xe10' more viable than standard receiver replacement 'H2-Replace'

- Xe30: Not viable comp. to 'H2-

${ }^{\star}$ Replace: $\sim 1 \mathrm{k} € /$ rec. (rec. $600 €+$ labour $400 €+$ Loop outage) ${ }^{* *}$ Repair/Fix : 200€/rec. assumed

- Xe20: Depends on point of time of damage
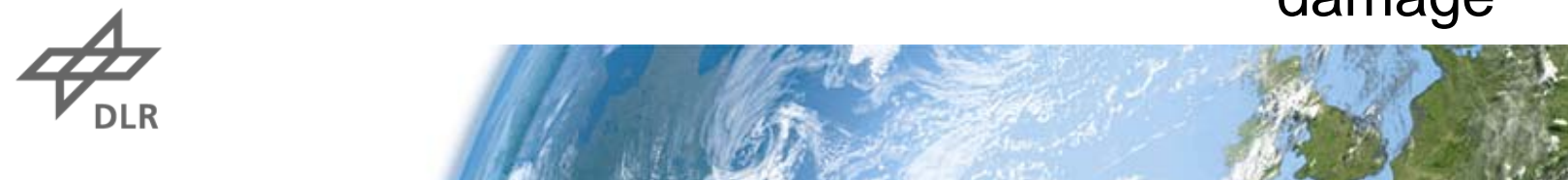


\section{RESULTS}

\section{Discounted Payback Period}
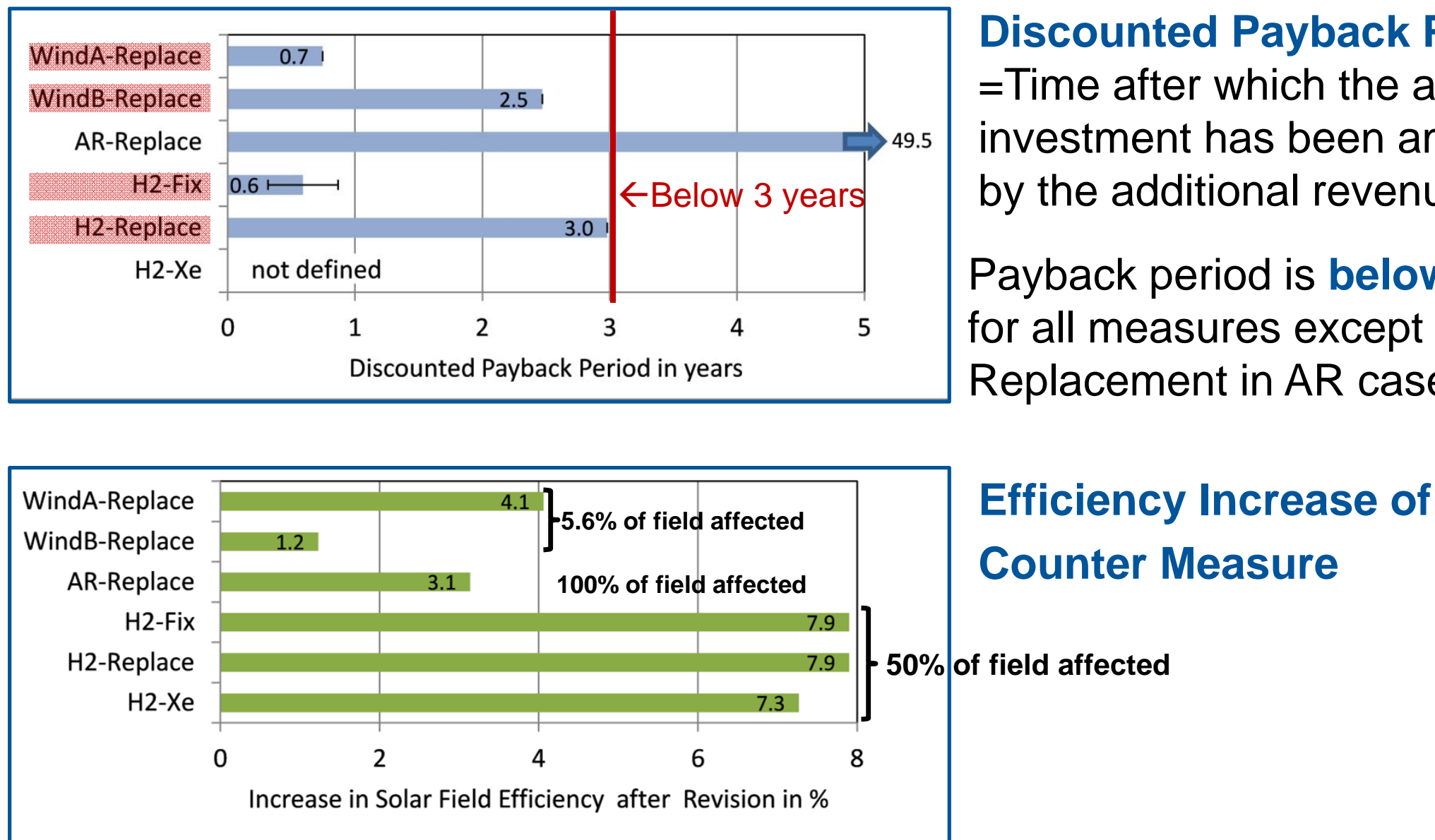

Discounted Payback Period $=$ Time after which the additional investment has been amortized by the additional revenues

Payback period is below 3 years for all measures except for Replacement in AR case

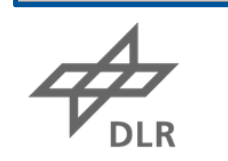




\section{Conclusions (I)}

- A method to investigate the energetic and economic impact of different receiver performance loss scenarios was presented.

- The software tool greenius was extended and coupled to Matlab

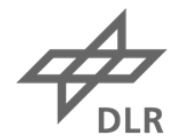




\section{Conclusions (II)}

The following results are of exemplary character and only valid under the assumed boundary conditions. Plant Owner should repeat the calculations for their own conditions with the proposed method.

- Reference: 150-MW $\mathrm{Ml}_{\text {el}}$-parabolic trough plant with 7.5-h-molten-salt-storage

- Scenarios: Wind breakage, $\mathrm{H}_{2}$ accumulation, anti-reflection coating degradation (AR) in event year 5,10 , or 15 and counter-measures

- Wind: Receiver replacement of receivers with broken glass envelope has a payback period of 0.7 to 2.5 years and hence replacement is strongly recommended

- $\underline{H 2}$ : Hydrogen accumulation has the highest impact, reducing output up to $11 \%$ and net present value by $77 \%$. Receiver replacement (payback 3 years) or repair (payback $\mathbf{0 . 6}$ years) is economically and energetically required.

- $\underline{H 2-X e}$ : The option of investing in receivers with Xe-capsule is a viable option, only if the surplus cost is lower than 10 to $20 \%$ and $\mathrm{H}_{2}$ accumulation occurs.

- AR: Replacement is NOT viable.
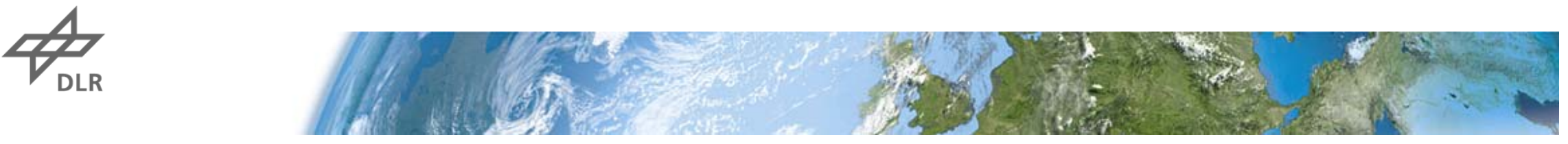


\section{THANK YOU}

\section{for your attention.}

C. Federal Ministry

for Economic Affairs and Energy

on the basis of a decision by the German Bundestag

We gratefully acknowledge the financial support from the German Federal Ministry for Economic Affairs and Energy for the two projects - PARESO: Contract no. 0325412

- FreeGreenius: Contract no. 0325427

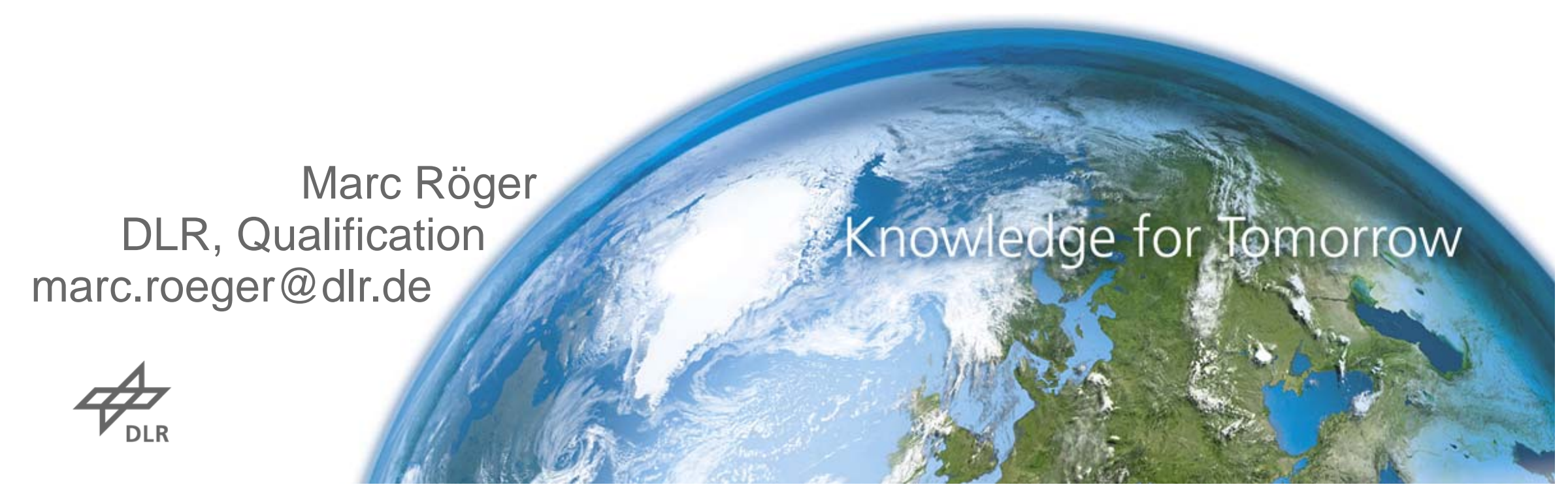

